

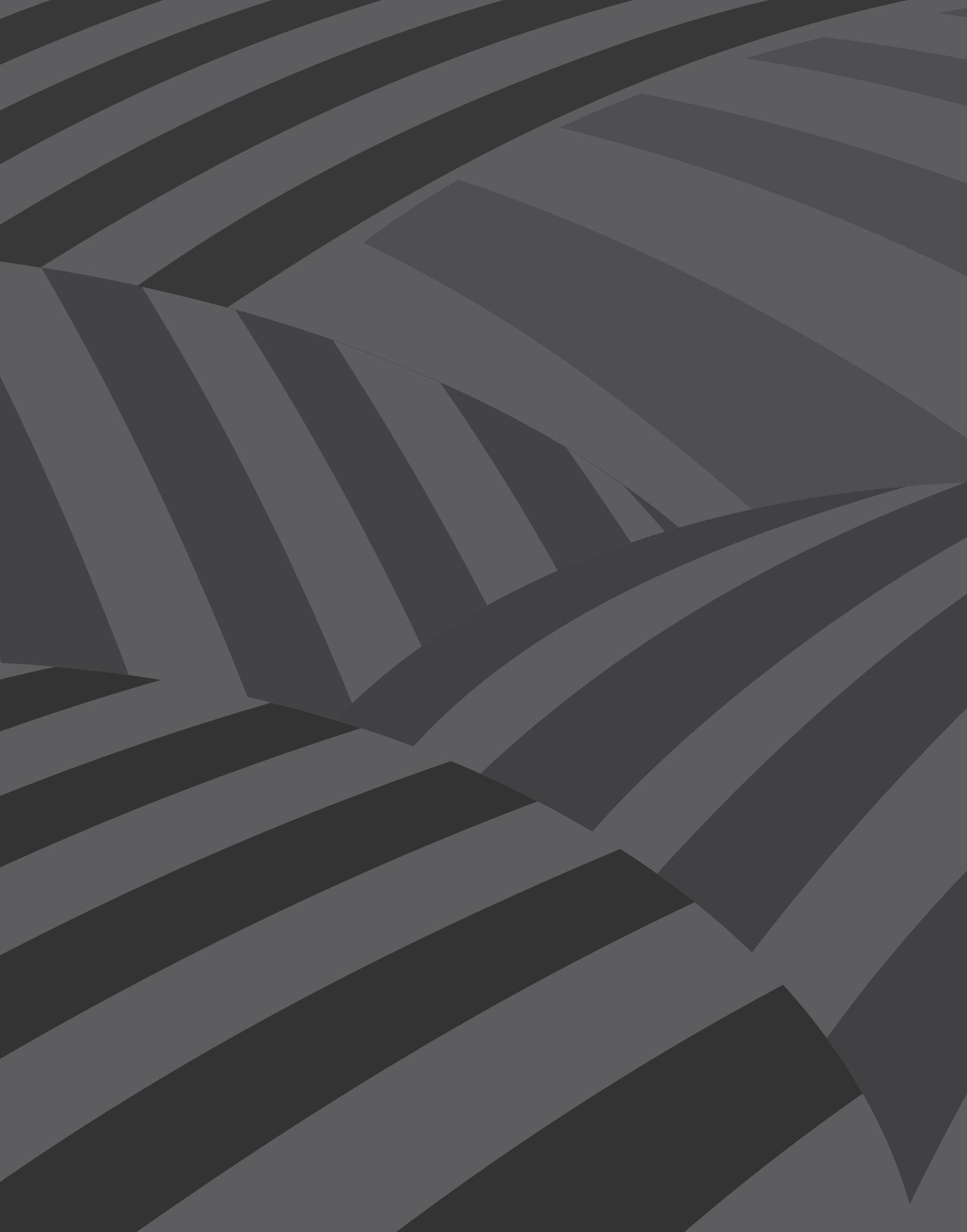




\section{Entre paros, pandemias y virtualidades: activismo político y trabajo colectivo}

Por Erasmo Daniel Ospina Ramírez*, Ángela María Sarmiento Camelo**, Paula Carolina Uribe Polo $^{* * *}$, Rossana Alarcón ${ }^{* * * *}$, Andrea Ramírez ${ }^{* * * * *},{ }^{* * * * *}$

Resumen: El presente artículo plantea una serie de articulaciones en torno a nuestra experiencia como estudiantes de la Maestría en Estudios Culturales de la Universidad Nacional de Colombia, y los trabajos de activismo y organización colectiva durante las movilizaciones del 2019 que nos condujeron, entre otras acciones, a la organización del ciclo de conferencias De la Sopa de Wuhan al Sancocho Latinoamericano, realizado a principios del 2020. Narramos, desde nuestra propia experiencia, cómo la cercanía que construimos entre nosotras propició la solidaridad y el acompañamiento mutuos, con lo cual pudimos afrontar los diferentes retos que nos generaron la pandemia y el aislamiento. Dicha cercanía se conformó en un proceso tanto por fuera como por dentro de la academia formal, pues si bien en las aulas leíamos sobre los estudios culturales británicos y norteamericanos, en la calle aprendíamos, por no decir escribíamos, los nuestros.

Palabras clave: Estudios posgraduales durante la pandemia, Estudios Culturales, anormalidad académica, Paro del 2019, crónica.

\section{Political activism and collective action between strikes, pandemics and virtualities}

Abstract: This article poses a series of articulations on our experiences as students of the Master's in Cultural Studies at the Universidad Nacional de Colombia, as well as the forms of activism and

* Sociólogo y maestrando en Estudios Culturales de la Universidad Nacional de Colombia.

** Licenciada en Lenguas Modernas y maestranda en Estudios Culturales de la Universidad Nacional de Colombia

*** Comunicadora social y maestranda en Estudios Culturales de la Universidad Nacional de Colombia

**** $\quad$ Artista Visual de la Universidad Javeriana y especialista en pedagogía de la Universidad Pedagógica Nacional

***** Profesional en Estudios Literarios de la Universidad Javeriana, promotora de lectura y bailarina.

****** Si se desea contactar a las autoras por favor escribir a mec.un2020@gmail.com. 
collective action that emerged during the 2019 national strike in Colombia, which eventually led to the organization of the forum "From the Wuhan soup to the Latin American Sancocho" in early months of 2020. We built narratives from our own lived experiences to inform how the togetherness built among us can be understood as a form of solidarity and mutual support with which we confronted the different challenges presented to us by the COVID-19 crisis. We argue that this togetherness is as a result of a process which occurred both outside and inside of the formal university setting; even though we used to read about the British and North American Cultural Studies, it was through taking the streets that we learned, and even wrote, our own.

Keywords: Graduate studies during the pandemic, Cultural Studies, 2019 Colombian National Strike, Chronicle.

Cómo citar este artículo: Ospina Ramírez, Erasmo Daniel; Sarmiento Camelo, Ángela María; Uribe Polo, Paula Carolina; Alarcón, Rossana; Ramírez, Andrea (2021). Entre paros, pandemias y virtualidades: activismo político y trabajo colectivo. Revista Controversia, 216, 287-327.

Fecha de recepción: 6 de octubre de 2020.

Fecha de aprobación: 10 de diciembre de 2020.

\section{Introducción: ¿Por qué narrar las experiencias de una Maestría en Estudios Culturales?}

n este artículo plasmamos una reflexión sobre nuestra experien-
cia como estudiantes de la Maestría en Estudios Culturales de la
Universidad Nacional de Colombia (UNAL o la Nacho), durante la pandemia generada por el virus SARS-CoV-2, causante de la COVID-19. Los motivos detrás de ello responden a dos objetivos: por una parte, hacer memoria de los retos que la pandemia generó en nuestros estudios posgraduales y de las maneras en que respondimos, y, por otra, caracterizar nuestro propio proceso formativo en aras de responder a los siguientes interrogantes: ¿Cómo se hacen estudios culturales en medio de un paro nacional, de una pandemia y del encierro?, ¿qué entrecruces entre trabajo académico y activista se producen en medio de estos contextos? y, sobre todo, ¿qué reflexiones sobre el presente que vivimos podemos hacer desde los estudios culturales que escribimos? 
El segundo objetivo se fundamenta en una de las propuestas más conocidas del campo de los estudios culturales, es decir, del contextualismo radical. Según lo entiende Lawrence Grossberg (2012), este implica el ejercicio metodológico de situar los estudios que se realizan en los contextos donde se están produciendo, o mejor dicho, de entender que todo conocimiento se produce en contextos específicos y responde a las problemáticas económicas, políticas y sociales de este. En ese sentido, más que un cuerpo teórico que funcione para cada situación, los estudios culturales se plasman como un campo de estudios que intenta generar un equilibrio entre "el deseo político, los recursos teóricos y el trabajo empírico" (p. 45), dicho de otro modo, "los estudios culturales se definen por su práctica” (2012 p. 36).

De tal manera, la propuesta de Grossberg implica un proyecto de contextualización del trabajo tanto académico como político, en el cual los objetos de estudio al igual que las prácticas político-académicas se sitúen según el contexto en cuestión; es por ello que los estudios culturales británicos no son los estudios culturales norteamericanos, ni los estudios culturales colombianos, ni mucho menos los estudios culturales que se hacen en la Universidad Nacional. Lo interesante de su idea es que más allá de que un contexto se limite a un territorio geográfico, o a los bordes de un mapa, estos se asemejan más bien a las coyunturas específicas que se articulan a partir de como se van viviendo, bien sean a través del espacio, del tiempo, de las fronteras del Estado-nación o de los límites formales de una institución. De allí el interés por caracterizar nuestros estudios culturales, pues consideramos: i) que las particularidades anómalas de los contextos que vivimos en los pasados dos años fueron las fuentes de las cuales bebimos para producir conocimientos y reflexiones al respecto; y ii) que a la vez nuestras acciones en estos contextos dialogaron con algunos saberes y recursos del campo. Precisado lo anterior, sin mayor preámbulo nos adentramos en la caracterización de dicho contexto anómalo. 
Ingresamos a la maestría en agosto de 2019, y tres meses más tarde - cuando apenas nos habíamos aprendido los nombres de nuestras compañeras y compañeros, y alguno que otro referente del campo de estudios - interrumpimos la normalidad académica para recogernos en la coyuntura nacional de movilización y paro. No fuimos indiferentes a los procesos de manifestación, cada una aportamos a la construcción de un trabajo colectivo que nos dio la oportunidad de participar como cohorte en las marchas, y luego en la elaboración de propuestas que nos permitieran seguir pronunciándonos en las calles. Este fue un momento importante para reconocer problemáticas estructurales de nuestro programa de maestría y con ello de los demás programas de posgrado de la UNAL, y ver que estas se cruzaban con las demandas de las protestas en torno a la educación superior.

Tras volver a clases y 'recuperar' el tiempo que estuvimos en paro, no tuvimos ni dos semanas del segundo semestre antes de que cerraran las puertas de la UNAL y entráramos en confinamiento obligatorio debido a la pandemia, y de nuevo alejarnos de los estudios del posgrado en condiciones de normalidad académica. Las clases, ahora desde la virtualidad, donde parece que se individualizan más las experiencias, nos han significado adaptarnos a nuevas formas de encontrarnos y potencializar las intenciones de trabajo colectivo, buscando otros canales y otras formas de mantener lo que habíamos construido juntas en las movilizaciones, en las clases y en otros espacios más espontáneos. Así, a medida que recordábamos todo lo que habíamos vivido en este año largo, encontrábamos que nuestra experiencia como estudiantes de la Maestría en Estudios Culturales ha estado marcada por unas coyunturas particularmente anómalas, que diferenciadamente habían afectado nuestras cotidianidades.

Los estados de emergencia en América Latina y el Caribe, como vía política para preservar el poder de los gobiernos democráticos, ante la amenaza de un virus desconocido y exotizado, implicaron parar con toda la vida social que hasta finales del año 2019 y comienzos del 2020 
veía su mayor esplendor en los movimientos estudiantiles, obreros, indígenas, afros, feministas, LGBTIQ + , campesinos y ambientalistas. La llegada de la COVID-19 a Colombia, un país caracterizado por dinámicas conflictivas y procesos de resistencia específicos, en nuestro caso repercutió en la imposibilidad de explicar cómo las opresiones se viven y se ejercen de maneras distintas en cada persona, de acuerdo a su sexo, género, color de piel o clase social, y cómo de manera sistemática y estructurada van desperdigándose por todo el continente. De la misma manera, las resistencias y las formas de lucha gestadas en las tensiones específicas de los Estados de América Latina y el Caribe nos han demostrado que estas también son compartidas tanto en las causas de su surgimiento como en las dinámicas, los performances, los métodos y las herramientas usadas.

En la Maestría de Estudios Culturales uno de los principales objetivos es ubicar la cultura no tanto como un producto, sino como una configuración de relaciones en contextos específicos y siempre cambiantes. La pandemia se nos presentó como el momento de mayor tensión y transformación de lo que considerábamos eran las movilizaciones sociales, el activismo y el compromiso político tan fuertemente inculcado en los textos y las aulas. Con todo ello, los estados de emergencia o de excepción en los que hemos estado sumidos todos durante la pandemia, pueden ser en realidad la regla: la creciente militarización de los campos y las ciudades, la represión y el uso de fuerza desmedida para sofocar marchas y movilizaciones, la precarización laboral, el racismo, la xenofobia, la homofobia, la misoginia, el machismo, la progresiva intervención extranjera, el repudio a la juventud, entre otros.

En medio del contexto de crisis económica incrementado por la pandemia, más de la mitad de las y los estudiantes nos vimos en riesgo de dejar la maestría y tuvimos que buscar maneras de responder ante la situación: presionar a los directivos para obtener plazos de pago, o incluso ayudarnos entre nosotros en los casos de mayor urgencia; así, con el tiempo fuimos encontrando en la acción colectiva un recurso para 
enfrentar las dificultades del momento. Sin embargo, ni esta respuesta ni la participación en las movilizaciones surgieron de la nada: las experiencias previas, como los paros del 2019, funcionaron como caldo de cultivo para que estas se consolidaran. Allí encontramos también la explicación a por qué consideramos valioso este ejercicio de narración de nuestras experiencias: porque en medio de la anomalía, sea esta un paro o una pandemia, hallamos maneras de responder ante la crisis y entenderla como un mismo espacio de formación.

Una de las ideas centrales que defendemos en este artículo es que nuestros estudios culturales, si bien se han visto atravesados por la anormalidad, e incluso afectados por diversas desigualdades y dificultades frente a lo que supone la normalidad académica, nunca han dejado de ser supremamente enriquecedores, pues hemos encontrado en estos contextos de crisis la posibilidad de participar de nuestro propio proceso formativo, ya en los entrecruzamientos con el activismo durante el paro; ya en los foros con dirigentes y académicos latinoamericanos y caribeños que se han realizado durante la pandemia; ya mediante el apoyo, los vínculos y lazos afectivos que se han creado con las compañeras, en los que varias de nosotras encontramos una razón para resistir tanto a dichas dificultades como a la propia dureza de las coyunturas que afrontamos.

Cabe entonces hablar de los diferentes momentos de este artículo. En un primer momento, realizamos una crónica en la cual pretendemos caracterizar nuestra experiencia desde que entramos a la maestría hasta prácticamente el momento de realización de este ejercicio. Siguiendo a Daiute y Lightfood (c.p. Aguilar, 2011), consideramos que "la manera en que las personas cuentan historias influencia cómo perciben, recuerdan y preparan eventos futuros” (p. 147), por esto intentamos construir un relato narrado a cinco voces sobre cómo vivimos esta experiencia.

Seguido de este momento, nos salimos un poco de nuestra narración y hacemos un ejercicio de reflexión y producción conjunta de sentido sobre un acontecimiento puntual: los foros que realizamos con activis- 
tas, académicas y académicos de América Latina y el Caribe sobre las movilizaciones de 2019 y las afectaciones de la pandemia. Nuestro interés en estos fue conocer en palabras de las y los actores cómo afectó la pandemia sus diversos procesos de movilización, y qué estrategias para afrontar el encierro y las problemáticas derivadas de la crisis se podían encontrar desde el activismo y la creación de conocimiento crítico, intentando rescatar los principales aprendizajes y sensaciones, que a su vez recogen varias de las reflexiones y conocimientos que realizamos frente a los contextos que nos interpelaron y cómo desde estos se pueden construir puentes con otras experiencias del continente.

Finalmente, en el tercer momento planteamos una reflexión un tanto más general alrededor de lo formativo que puede ser un espacio de pandemia, crisis o excepción, o al menos de lo formativo que fue para nosotras. En esta, concluimos que tanto las maneras en que afrontamos la pandemia como las reflexiones que hicimos responden a la consolidación de una solidaridad mutua que entretejimos como estudiantes y que, a su vez, se entretejió en la propia experiencia vivida durante las dos coyunturas.

\section{A). Crónica: desafiando la soberanía de los Estudios Culturales}

Partiendo de una lectura detenida de algunos fragmentos del texto Affect and Emotion. New Social Science Understanding, de Margaret Wetherell, proponemos a continuación una interpretación del fenómeno de la octava cohorte de la Maestría en Estudios Culturales, de la que hacemos parte, empezando por argumentar que la actividad afectiva que entre nosotras tiene lugar, podría ser interpretada a la luz del concepto de "prácticas afectivas”, es decir, procesos en los que se ensamblan una variedad de emociones y experiencias que encuentran un lugar en nuestros cuerpos, y por las cuales ciertos sentidos son creados/producidos. Prácticas compuestas por episodios, escenas o performances afectivos, siguiendo la argumentación de Wetherell, que constituyen un flujo constante de afectos, con momentos de mayor y menor intensidad, cuya existencia se sigue 
extendiendo en el tiempo. En nuestro caso, estas prácticas se han ido configurando en el curso de nuestros encuentros y acciones conjuntas, de nuestras conversaciones y reflexiones, constituyendo una experiencia de grupo que es difícilmente estática y homogénea.

Según Wetherell (2012), "el afecto demuestra fuertes tendencias hacia los patrones, pero también señala problemas y disturbios en patrones existentes" (p. 13). Deducimos que habla de patrones en el sentido de modelos, como los patrones de migración, los de modernización, de sentimientos, que para el estudio de los afectos ella propone comprender como “dinámicos, múltiples e interseccionados” (p. 16). Diríamos, de vuelta a nuestro caso, que se compara a la tendencia hacia la formación de un grupo de amigas y compañeras de estudio, con ciertas características más o menos comunes a otros grupos como estos, pero también con cualidades particulares que reclamamos como diferenciales de cara a otras experiencias de grupo.

Así, se trata de un fenómeno para el cual resulta provechosa una interpretación desde el enfoque de las prácticas afectivas, en su condición situada y conectada con otras prácticas sociales, para evitar versiones limitadas y simplificadas sobre lo emocional, u homogeneizar la diversidad de elementos que las componen, sobretodo en estos fenómenos colectivos. Las acciones que hemos cristalizado como cohorte están íntimamente relacionadas con fenómenos y prácticas que exceden los espacios y las circunstancias con las que hemos estado directamente implicadas. El paro nacional de 2019, en cuanto movimiento colectivo y masivo de acción política; la pandemia del coronavirus, que nos obligó a distanciarnos y a llevar nuestros encuentros a otros escenarios; las irregularidades al interior de la UNAL en la administración de unos recursos, especialmente en las circunstancias actuales, son algunos de los fenómenos con los que nuestras prácticas afectivas están conectadas.

A la luz de esta primera reflexión sobre el concepto de prácticas afectivas, en la crónica sobre nuestras experiencias como cohorte resaltamos 
los episodios de esta índole que han sido claves en la consolidación de un habitus de grupo. En palabras de Wetherell (2012), siguiendo y desarrollando la propuesta de Pierre Bordieu, el habitus surge a través de "la adaptación inteligente y reflexiva a nuevas circunstancias, (...) en la medida en que las personas ponderan y sufren angustias por los patrones en sus vidas, a raíz de lo cual toman decisiones y resisten a las fuerzas que parecen moverles en direcciones que sienten como equivocadas” (p. 105). Es en esta clave que buscamos comprender lo narrado a continuación, y su relación con nuestra apuesta por el trabajo colectivo y el activismo político desde la academia.

\section{I: Primeros encuentros}

Cada una de nosotras llegó a la maestría enfrentando situaciones diferentes. Desde la admisión, la coincidencia derivó en la posibilidad de sentir que hacíamos parte de un espacio común, en el que expresamos y experimentamos sensaciones y reflexiones particulares relacionadas con el papel de la cultura en las luchas políticas, las transformaciones de estructuras sociales desde lo simbólico, la posibilidad de hacer algo más con la literatura, las prácticas artísticas, la pedagogía, o ampliar los horizontes de sentidos en el trabajo de campo. Significó una segunda oportunidad que se concretó entre la indecisión y la indefinición ante el futuro profesional y el entusiasmo de un campo que se comprendía vagamente; pero también un volver sobre los recuerdos de textos leídos en una época ahora distante, aunque siempre presente en expectativas atadas a los sentidos construidos alrededor de nociones, donde la desazón de la dominación y las construcciones de los otros nos dejaban sin aliento y con ruidos incesantes en los oídos. Fue también una continuación en la experiencia universitaria, la ilusión de un ascenso natural - pregrado, maestría, doctorado, posdoctorado y demás-, una oportunidad para reencontrarse con una intención olvidada, o simplemente el continuo de una formación académica ocupando nuevos espacios que son a la vez familiares, es decir, entrar al edificio de posgrados de la UNAL ahora como estudiantes. 
Los retos a asumir en este nuevo paso también están ligados a la timidez e inseguridades personales, a la presión que sentíamos por la exigencia académica, los cuales se fueron desdibujando a medida que nos conocíamos.

Esas primeras clases y encuentros en el aula significaron entrar a escuchar las voces y las disonancias entre las trayectorias, en ese momento tan diversas y lejanas, de cada una de las personas sentadas alrededor de una gran mesa cuadrada, con el profesor Fabio López de la Rocha dándonos la bienvenida a la clase — ¡clase de 7:00 a.m.! - antes de sentarse en la palabra. Fue extraño para muchas de nosotras encontrarnos con un grupo mayoritariamente masculino, especialmente para quienes veníamos de campos en los que las mujeres suelen tener una presencia fuerte.

Las dimensiones teóricas y las diversidades de unas y otros empezaron a plantearnos interrogantes y angustias a las que hoy podemos dotar de sentido pleno, y sobre los que aún podemos discutir y debatir, ya no con el mismo afán de esas primeras sesiones por definir el concepto de cultura, pero sí con la intensión de entender de dónde provenían esas diferencias que todas identificábamos en nuestra propia concepción de los estudios culturales.

"Vamos a entender de qué se ocupan los Estudios Culturales", pensábamos a las 7:00 a.m. cada miércoles en clase de Teorías I, con el profesor Mauricio Montenegro. "Estamos hablando siempre de procesos culturales, no del estudio de productos culturales. Hablamos del estudio de procesos de cultura popular en articulación con el poder”, nos decía Mauricio. Esa primera definición fue decisiva, pues nos permitió empezar a pensar un campo diverso pero a la vez singular, que estaba motivado por lo que para todas fue muy importante: la búsqueda de una transformación desde el activismo y el trabajo con otras y otros. En nuestros diálogos, nos dimos cuenta cómo nuestras posturas eran similares, y más allá de la militancia resultaban inscritas en una corriente de 
pensamiento emancipadora, libertaria, comunal, anarquista, feminista y decolonial. Esto nos permitió también comprender que, alrededor de ese conocimiento académico, existía la posibilidad de empezar a enlazar unas inquietudes personales, con la validez de la interpretación y las experiencias propias.

\section{II: La Parva, el bar de siempre}

"Lo que comienza como un espacio indiferenciado se vuelve lugar en la medida en que lo conocemos mejor y le asignamos un valor" (Yi-Fu Tuan, 1977, p. 6, c.p. Aguilar, 2011).

La cercanía que establecimos y la tranquilidad con la que todos nos empezamos a relacionar fue un alivio. No había exigencias ni reparos a la hora de comenzar a conocernos. Solo teníamos expectativas que nos permitieron descubrir en las clases, y fuera de ellas, un lugar para escucharnos y comprender poco a poco que teníamos una cercanía e ideas similares respecto a la vida misma. Cuando empezamos a darnos el espacio para salir del ámbito académico, continuábamos con las discusiones de las aulas y también empezamos a forjar amistades. Ahí empezó un ciclo de ambigüedades. Querer estar allá y acá. Querer lo nuevo y la tradición.

Encontramos cómo conjurar nuestras otredades, porque eso éramos en esencia, personas diversas interactuando en espacios de encuentro. Construimos una suerte de complicidad comunitaria y con intencionalidad, unas prácticas, unos rituales que traspasaron las aulas y se instalaron en los espacios que rodeaban "la Nacho", a los que concurríamos después de las 8:00 p.m. Juntamos intencionalidades en un afán por encontrarnos, en un intento quizás de tender puentes entre nuestros caminos, experiencias vividas, edades, roles y afanes. Nos encontramos y desencontramos en discusiones que sacamos de las aulas y llevamos a dimensiones más cotidianas, prácticas íntimas y cercanas, en las que más que puentes construimos vínculos, unos vínculos que no pueden 
denotarse como inocentes. Allí nos descubrimos acogiendo y destruyendo nuestros cánones, los pusimos a prueba y nos lanzamos a abismos en los cuales la complicidad y el cuidado forjaron sentidos, sentimientos y emociones de los que resultaba cada vez más difícil desprenderse y que se iban volviendo parte del transitar los estudios culturales.

Esas complicidades se construyeron en un bar de la esquina, compartiendo un cigarro, tomando tinto después de las clases, en el "crack" de un paquete abriéndose, el aroma de papitas, galletas, maní que penetraba todo el salón. Ese momento de compartir comida en la clase con la profesora Marta Zambrano, esa confianza de pasar de mano en mano y contagiarla de ese ritual, es como ¡uff! ¡la profe copió!, o junto a las escaleras de Sociología, en las marchas, en los plantones y ahora tras unas pantallas.

Y los jueves de La Parva, el bar de siempre. La emoción en el estómago cada vez que sabíamos que íbamos a quedarnos charlando, tomándonos algo, conociéndonos más. Todas y todos éramos parte de esas salidas que son el eje de nuestra relación de amistad. ¡Fuimos a La Parva ¡incluso con el profe Fabio! Eso fue muy bueno. "Vamos después de eso a un bar". Sentarse en un banquito junto a esas otras cinco o seis personas que apenas estábamos conociendo. Pola uno, pola dos. Casi aguardiente, pero no. ¡Delicioso! Desde la primera conversación. “¡Adrián! ¿Cómo así que Alfredo Molano revisó tu trabajo?”.

La Parva era y es para nosotras, citando a Yi-Fu Tuan (1977, p. 13), un "lugar como la forma clave de comprender el espacio a partir de la experiencia del sujeto y con toda la carga de sentido que dicha experiencia lleva consigo. (...) Lugar como espacios delimitados, con límites precisos, que para los sujetos representan certezas y seguridades otorgadas por lo conocido” (c.p. Aguilar, 2011).

Estos lugares han marcado el curso de cada compañero y compañera de la Maestría en Estudios Culturales de maneras distintas y en momentos 
importantes. Quizá, porque en esas relaciones de afectos hemos podido encontrar unas formas de trabajo político y académico potentísimas, fructíferas y críticas frente a las maneras competitivas e individualistas usuales en los espacios universitarios. Eso no se ha disuelto durante la pandemia. Buscamos otras maneras de encontrarnos y aparecieron otros canales y formas de mantenernos activas y seguir trabajando juntas, que relataremos más adelante. Esto fue posible también gracias a las propuestas que emergieron de las clases, como la de Feminismo Decolonial, con la profesora Ochy Curiel, quien nos dio la posibilidad de pensarnos las experiencias académicas para considerar los aprendizajes desde prácticas colectivas y activistas que permiten conectar las aulas con el mundo y sus realidades.

No todos los grupos son así, y quizá podemos caer en una especie de romantización, pero realmente así nos sentimos: parte de un parche que se ha construido y consolidado en momentos de ocio, cuidado, amistad, trabajo académico y activismo dentro y fuera de las aulas.

\section{III: Organización política y desorganización cultural}

¡Por unos posgrados críticos y organizados: Estudios Culturales al Paro y contra el Para!

A quienes llegábamos por primera vez a estudiar en la UNAL nos habían dicho innumerables veces que entrar a ella suponía "entrar en paro” cada tanto, y que eso era un problema porque nos íbamos a atrasar. Sin embargo, nuestras inquietudes políticas, para muchas abiertamente manifiestas, encontraron un lugar y unas circunstancias dónde articularse y materializarse. Hallaron su curso para fluir y potencializarse, en medio de la ansiedad, la adrenalina, el miedo y la sensación de estar frente a algo que retaba nuestro temperamento, muchas veces obediente, juicioso, perfeccionista y pasivo. 
Para cuando se empezaron a convocar los paros, cada jueves entrábamos a clase al ritmo de las aturdidoras y del sobrevuelo del helicóptero de la policía; parecía como si ignoráramos el mierdero que había afuera. Nos sentimos interpeladas por la movilización social desde un lugar cercano, que antes desde la distancia hacia ruido y ahora amenazaba con quebrantar la posibilidad misma de estar allí, en ese espacio donde logramos ser, estar y sentir. No recuerdo cómo llegamos a hablar de tomar acciones sobre lo que nos interpelaba del contexto del paro nacional. Empezamos a enviarnos cosas entre el grupo de WhatsApp compartiendo lo que ocurría a nuestro alrededor, pero sobre todo en el espacio de la educación pública. Desde nuestros lugares específicos cada unx identificaba ciertas cosas que nos interpelaban de la convulsa situación del país.

Se planteó escribir conjuntamente un comunicado para sentar nuestra posición, la cual ya había sido discutida en varias ocasiones fuera y dentro de las aulas. "Organicémonos, escuchemos a Henry, el representante de la cohorte anterior, hablemos con los profes”. Funcionó. "Convoquemos paro, que nadie sabe para qué te sirve a ti, pero aprovechemos la coyuntura nacional y la descoyuntura interna”.

En La Perola debatimos las formas y el fondo; acudimos a los saberes y prácticas de quienes hacen del arte una forma de vivir, sobrevivir y habitar el espacio. Configuramos encuentros para definir el cómo, cuándo y dónde de una forma de activismo que apenas vislumbrábamos como posibilidad. Empezamos a establecer propuestas gráficas que pudieran servirnos para movilizar y condensar nuestras reflexiones hacia otros públicos. Fue el inicio del trabajo activo en las movilizaciones y lo que teníamos por delante, con el compromiso de responder como profesionales y estudiantes de posgrado a la realidad del país y al sueño de un cambio. Acción política. Planeación, creación. Ideas abstractas en grupos de WhatsApp y bisturí concreto en la práctica. Entre rones se nos ocurrió tal cosa, en medio del guayabo llevamos las ideas a acciones, y es que la acción política es un complejo raro. Puede ser un capital, pero a su vez puede ser un flujo, es decir, puede ser un acumulable de técnicas, saberes 
y reconocimientos, o por su contraparte, puede ser algo que espontáneamente va ocurriendo en la marcha. Y fluía... era delicioso. Discusiones con los profes, disensos con compañeros, correos en visto; pero acción. Movimiento. Todo eso que no necesita reflexión inmediata, sino para las ponencias futuras: todo eso fue allí.

El $21 \mathrm{~N}$ fue cumbre, salimos como grupo de estudios culturales y nos entregaron el trapo de la anterior cohorte. Fue casi un ritual en el que se pasaba la batuta. Luego, la confrontación, la gaseada, la lluvia, el miedo de que nos cascaran. Ese día no pudimos culminar la marcha; los "tombos” nos hicieron devolver al campus y adentro nos pegaron la gaseada de la vida. Alguna de nosotras, incluso, chupó gas como nunca antes y reconoció que jamás había visto tal tropel en todas las entradas de la Nacional, que es gigante, como sucedió ese día. El paro nacional del $21 \mathrm{~N}$ nos puso de frente ante la posibilidad de ser atravesadas e impulsadas por el contexto, de estar situadas en disputas que desbordan nuestras realidades particulares y nos insertan en una trama local y nacional de la que no podíamos ni queríamos escapar. Esto nos interpelaba radicalmente; la trama local se nos presentó desde el lugar de una maestría desfinanciada, una realidad que no es ajena a muchos de los programas de posgrado dentro de la UNAL, que hace parte de la problemática y de las demandas asociadas a la educación superior, pero que no suele ocupar un lugar fundamental en estas, igual que los posgrados que son excluidos de decisiones administrativas importantes, y se excluyen en escenarios asamblearios conformados y consolidados por estudiantes.

Pocos programas de posgrado entraron en paro definitivo, entre esos el nuestro: la Maestría en Estudios Culturales. Vimos en el $21 \mathrm{~N}$ una posibilidad de jugarnos las reflexiones de las aulas en un campo de disputa mayor: las calles. En ese momento pudimos sentir de manera concreta ese llamado al compromiso político que continuamente leímos y debatimos en clases de la maestría. 
Todo empezó a tener sentido aquí. Estábamos integrando lo que leíamos con acciones reales que se materializaban en nuestros diálogos, las producciones gráficas que empezamos a concebir $\mathrm{y}$, finalmente, la clase a la calle que llevamos a cabo el 17 de diciembre en el portal de Transmilenio de Las Américas. ¡Suerte el salón y la clase como la conocíamos!, bienvenida la calle. Bienvenida la clase a la calle.

Hicimos parte de unas decisiones comunes que nos llevaron a articular nuestro proceso académico con el político. Mauricio Montenegro nos decía algo que recordamos siempre: “Organización política y desorganización cultural”. Muchas de nosotras éramos, en ese momento, pura desorganización personal. El país vivía cosas que la teoría no entendía, que nuestras teorizaciones tampoco entendían, pero eso no nos detuvo. La frase tenía sentido, incluso en medio del sinsentido que vivíamos. De la clase a la calle podemos decir que en esta experiencia encontramos un espacio de defensa de apropiación y de trabajo colectivo que aún hoy recordamos con cariño. Lo interesante es que el dar se convirtió en el recibir. Sentarnos en una estación de Transmilenio a escuchar, ya no era invertir un capital, es decir, no era asistir a una asamblea o formarnos como cuadros políticos; era aprender de otras y otros; era dialogar con personas con quienes jamás habríamos compartido en la UNAL o interactuar en espacios donde los estudios culturales no eran un campo sino un desconocido.

Aquel momento nos mostró lo artesanal que es el sentido. Y tal vez esa es la mejor imagen de ese paro. Un paro en el cual un montón de gente se puso a quemar sus arcillas sin forma, para encontrar en el camino que sí la tenía. Para muchas de nosotras este fue el primer escenario en el que entendimos lo que significaba participar de primera mano de la creación de unos sentidos colectivos, de la posibilidad de reclamar unos espacios, de movilizarse política y corporalmente con otras y otros, abrazando unos sentires que eran, de una $u$ otra forma, colectivos, o que al menos se hacían comunes para poner a vibrar esas calles que nos tomábamos. Fue asombroso. Lo que vivimos a finales del 2019 
fue una verdadera transformación personal, un conectarnos con una cantidad de experiencias que nos importaban, que queríamos conocer, que estaban conectadas con lo que estudiábamos, con lo que creíamos.

\section{IV: Salvar el semestre}

El año acabó en medio de todas estas sensaciones, con los ecos de las calles aún en nuestros cuerpos. El 2020 prometía más y más cambios, nuevas movidas colectivas, transformación. Pero la cosa no parecía tan prometedora por otro lado: el de las responsabilidades académicas. Aún no terminábamos el semestre, estábamos repletas de entregas pendientes. Continuamos compartiendo imágenes de las movilizaciones, invitaciones a seguir en las calles, a pensarnos un 2020 en el cual no solo retomaríamos ese primer semestre pendiente, sino las intencionalidades que nos llevaron a parar para avanzar. ¿Hacia dónde? No estaba muy claro, pero compartimos el impulso, y también el cansancio y la incertidumbre. Ahora se trataba de salvar el semestre en suspenso, recuperando espacios de discusión y las últimas sesiones de cada clase. No fue fácil, y a la luz de ese quiebre que asumimos como cohorte para salir a las calles, nuestros trabajos finales ahora parecían una tarea titánica.

"Salvar el semestre" era una expresión bastante frecuente en la Universidad. Respondía a ese espíritu griego de conquista, de enfrentarse a un gran titán sin mayor cosa más allá de una lanza. Respondía a esa semana en que la hemeroteca volvió a abrir 24 horas, y empezamos a vivir entre la degradación físico-moral y los caldos de dos mil pesos que dan a las tres de la mañana. Pero ese era el compromiso que nos habíamos fijado mientras que, simultáneamente, continuábamos atentas a lo que sucedía en las calles. Notas, trabajos finales, pretensiones, límites de páginas violados. Retomar un semestre así, con un pie en la calle y el otro en los salones, es algo contra lo cual siempre te previenen, pero nunca entiendes hasta que lo vives. 
Al final se nos hizo el milagrito. Entregamos, respiramos hondo y celebramos. Claro que celebramos, eso nunca nos ha faltado. Mientras tanto, el eco de la COVID-19 sonaba cada día más fuerte en noticias y en redes sociales. Una cosa que parecía lejana y que aparentaba estar "al otro lado del charco" se fue metiendo poco a poco en nuestra cotidianidad. Entre estas noticias; nuestras incertidumbres por el devenir del paro y la movilización de cara a un 2020 que ya se sentía diferente; las inquietudes políticas sobre la crisis económica, la corrupción, el desempleo, la persecución; los ataques en incremento a jóvenes y liderazgos sociales; la militarización de las ciudades o las violencias contra las mujeres, que no cesaban, se mezclaban con nuestro interés por continuar compartiendo y transformándonos juntas dentro y fuera de la academia. Nos preparábamos para nuestro segundo semestre de maestría.

\section{V: De la Sopa de Wuhan al Sancocho Latinoamericano}

El 27 de febrero de 2020 empezamos el segundo semestre. Sensaciones de cierta incertidumbre después de la euforia de las movilizaciones y el cierre, a las carreras, del primer semestre, se mezclaron con la emoción de tener clase con Ochy Curiel, la promesa de descolonizar nuestras prácticas en espacios académicos. Por otra parte, en la clase de Teorías de la Cultura II surgió la pregunta de la profesora Martha García sobre nuestras intenciones de articulación con aquello que mencionamos en el primer comunicado como cohorte, de cara al paro nacional: intervenir desde las problematizaciones y comprensiones sobre la agitación social que nos contextualiza, ahora vista desde los Estudios Culturales en América Latina y el Caribe. Nos imaginamos un gran cierre, saldríamos de nuevo de las aulas. Ese paso a la calle se articulaba a un nuevo espacio académico, la propuesta ahora se expandía y prometía acercarnos a una mayor comprensión de las movilizaciones del 2019, esta vez en toda Abya Yala. ${ }^{1}$

1 Nombre que los indígenas kuna, ubicados entre Colombia y Panamá, dieron al continente americano antes de su colonización. Su uso responde a una posición política respecto a las representaciones hegemónicas, coloniales occidentales. 
Marzo 6 de 2020: viernes por la noche, en un restaurante muy cerca de la Nacho, por la entrada de la calle 26, tuvo lugar la cena de celebración de cierre del primer semestre, organizada por la querida Alicia Vega, secretaria y alma del programa de Maestría en Estudios Culturales. Faltaron algunos compañeros y compañeras, también profes; añoramos la presencia del profesor Fabio López y de la misma Alicia. Mientras tanto, las noticias se atiborraban de pánico ante la confirmación de los primeros casos positivos de COVID-19 en Colombia.

A pesar de todo, fue un cierre de semestre bonito, en especial la borrachera de la noche anterior en La Parva, pues fue como todas las de la maestría: incoherente y espontánea. Lo que nadie imaginaba era que ese día sería la última visita que haríamos a ese bar. Un par de semanas después llegó el desencanto: ¡COVID! ¡Cuarentena! Desesperación y ansiedad. El desgarro que parecía entonces exagerado ante una amenaza invisible aún incipiente, embargó los ánimos de todos y todas. Algunas consideramos parar el semestre, cancelar y esperar a que todo volviera a la normalidad, pero en una maestría que sucede cada dos años esa posibilidad también resultaba amenazante. La tristeza y el desánimo se apoderaban hasta de las voluntades más férreas.

Continuar el segundo semestre con todas las condiciones que surgieron fue muy difícil. Las distancias asumidas desde la virtualidad nos quitaron a todas las oportunidades no solo de asistir al espacio universitario, a las clases, a la Universidad, sino también de encontrarnos en donde siempre teníamos diálogos y discusiones que enriquecían nuestra actividad académica y también nuestra vida personal. De cara a las rupturas, las transformaciones, los procesos tensos, dolorosos y conflictivos que hemos atravesado desde nuestras individualidades, volver a encontrarnos es una promesa que soñamos.

Seguimos un semestre sin mayores comprensiones de lo acaecido en medio de la incomodidad, los cambios y la poca familiaridad con las plataformas que hacían posible seguir en clase, mientras el país y la 
misma Universidad nos escupía en la cara las desigualdades en el acceso a la educación, ahora desde la falta de dispositivos y conectividad; la pauperización del trabajo con unas condiciones agudizadas por la pandemia que a muchas nos dejó sin recursos, en medio de situaciones laborales precarias, o sin las horas de descanso, inundando los espacios que creíamos separados de los ambientes personal y académico. Aquellas condiciones por las que meses atrás habíamos reclamado en las calles, se desnudaban y recrudecían en nuestras realidades y nos dejaban unos espacios ahora angustiosamente vacíos.

Una de nosotras propuso llevar la discusión alrededor de las movilizaciones a un foro, otra forma de protestar sin calle. A la respuesta afirmativa de todas siguió un ánimo ferviente por contribuir, desde las clases, a construir un escenario que nos permitiera articular la situación actual con las múltiples preguntas sobre las manifestaciones y sus posibilidades en la contingencia derivada de la COVID-19. Reafirmamos una vez más esa unión que nos caracteriza, para pensarnos en la posibilidad de articular una propuesta que dio resultado en el foro De la Sopa de Wuhan al Sancocho Latinoamericano, y que construimos de la mano con los y las compañeras de la Maestría en Estudios de Género.

No pensábamos que fuéramos tan fuertes y dinámicas, que lográramos sacar un foro virtual de talla internacional, y todo hecho por nosotras, estudiantes, con la ayuda incondicional de las profesoras Ochy Curiel y Martha García. A ellas, igracias!

Aquello que resuena constantemente en los planteamientos de proyectos y que se denomina transdisciplinariedad, se concretó en una propuesta que para todas fue una luz de esperanza y trabajo colectivo soñado: realizar este foro fue algo orgánico, que tuvo que ver con que todo el mundo hacía lo que podía hacer, lo que le venía cómodo, lo que había explorado en otros lugares y que aquí podría estallar. Los foros no eran una nueva etapa en la vida, sino una leve continuación de esta, y eso alimentó las ganas de movernos. 
Significó un trabajo arduo, comprometido y sobre todo gratificante, que nos devolvió parte de lo comunitario a nuestras prácticas; nos articuló en la búsqueda de esas voces y experiencias vividas en las movilizaciones de 2019 en varios países de América Latina. Este ejercicio, si bien puso de relieve unos nudos problemáticos en los cuales se encontraban varios países, nos permitió también acercarnos a la filigrana de cada lucha.

De Chile, revisamos las protestas que estallaron en octubre tras la subida del pasaje del metro, un detonante que destapó las cuestiones de fondo: una alta desigualdad social, unos salarios bajos, unos servicios costosos, incluido el de la educación, un sistema de salud en crisis y una ciudadanía endeudada.

De países del Caribe como Haití y República Dominicana, examinamos las políticas que recrudecen la crisis económica, el racismo, la xenofobia y la militarización en aumento, y que detonaron masivas movilizaciones reprimidas brutalmente. Las voces de mujeres que han liderado procesos de resistencia resonaron con fuerza y fueron protagonistas en este foro.

De Ecuador, exploramos el paro y la salida de amplios sectores de la población a las calles en contra de las medidas del gobierno de Lenín Moreno, una de las más sonadas la supresión del subsidio a la gasolina, aunque el paquete incluía recortes y reformas laborales y tributarias que se traducirían en un detrimento de las condiciones de vida de las poblaciones ecuatorianas, sobre todo de las más marginalizadas (Astarita, 2019).

En Bolivia, el golpe de Estado contra Evo Morales desvistió la pugna por los poderes simbólicos que ostentan la herencia del colonialismo en objetos como la biblia, la cruz y la quema de La Whipala, al son de las arengas para volver a la democracia blanca. Tampoco el Gobierno de Evo escapó de las críticas de quienes repudiaron el golpe, pero que no sintieron representatividad por la condescendencia con políticas neoliberales, machistas y autoritarias. 
Por parte de Brasil, las políticas de muerte, control y vigilancia hacen parte de una estructura racista que recae en la polarización social y cultural. Los cambios abruptos entre gobiernos de izquierda y de derecha han sido el escenario para la irrupción de movimientos y luchas reivindicadoras y emancipadoras, siendo protagonistas las colectivas feministas antirracistas, con reclamos claros por defender la alteridad, la heterogeneidad y la desmilitarización.

En México, las movilizaciones feministas son protagonistas. Una diversidad de problemáticas coyunturales e históricas se unió en un momento en que la rabia estalló frente a los monumentos nacionales, las plazas, las fachadas de los recintos de gobierno y las avenidas principales. La trama del narcotráfico, las disputas territoriales, la corrupción, la misoginia, el empobrecimiento y las violencias contra las juventudes, remarcan el estallido feminista mexicano.

No escatimamos en nada: desde el bautizo del foro, hasta el arte de las piezas gráficas, el aprendizaje del manejo de plataformas y las transmisiones en directo (streaming) nos tocaron fibras, nos reunieron, nos dieron un impulso, nos devolvieron al lugar de lo político, un lugar tan marcado en la pregunta por la cultura de los estudios culturales. El evento fue un sancocho latinoamericano en medio de Todas esas voces, las experiencias, el trabajo político y la trayectoria académica de las y los invitados.

La llama está encendida en Abya Ayala, el curso de la historia no se detiene y el sueño de una América dueña de su propio destino ha sido el motor de las luchas y las resistencias contadas en esos tres días de foros virtuales.

Terminar el semestre con la satisfacción de haber cumplido con el foro y de haberle dado esa magnitud a nuestra articulación con la Maestría en Estudios de Género, con cada uno de las y los invitados a quienes tuvimos el placer de escuchar, nos llenó de satisfacción. Sin duda algu- 
na estábamos en “otro lugar”, en la ausencia de un lugar físico común, pero en-presencia, porque nos habíamos creado nuestro propio espacio. Y ahora, ¿cómo íbamos a continuar?, ¿cómo seguir apoyándonos de cara al inicio de nuestras investigaciones y de un tercer semestre de clases?

Y aquí estamos, en el comienzo del tercer semestre, narrando esa experiencia que nos marcó a cada una y que nos ha significado tanto.

\section{B). Sobre los tres días de foro}

En este apartado hacemos una reconstrucción de las voces y aportes de los y las participantes en los tres días del foro De la Sopa de Wuhan al Sancocho Latinoamericano. En el ejercicio de recoger las memorias del evento, distanciando nuestras voces, nos interesa condensar e hilar las propuestas y el trabajo que cada una de las participantes compartió para hacer visibles y describir las realidades que las interpelan de cara a la pandemia, y que hacen parte del reconocimiento de unas problemáticas que edificaron las manifestaciones del 2019 en su respectivo país. Las invitadas participaron activamente durante las movilizaciones desde sus experiencias, acciones y saberes y las de sus comunidades. En el proceso de diálogo construyeron reflexiones importantes con las otras, en las que se hicieron visibles las particularidades, pero sobre todo, la cercanía de las problemáticas que enfrenta Abya Yala. Esto nos permitió entretejer sus aportes y propuestas en el reconocimiento de unas posibilidades de movilización durante el 2020, que nos han permitido, hasta el día de hoy, reflexionar sobre nuestras propias prácticas.

Durante el foro contamos con la participación de Katy Machado, representante de Ecuador, exdirigente de la Confederación de Nacionalidades Indígenas del Ecuador (CONAIE) y defensora de los derechos colectivos y de la naturaleza; Ángela Yesenia Olaya, investigadora asociada y coordinadora académica del Certificado en Estudios Afrolatinoamericanos, en el Instituto de Investigaciones Afrolatinoamericanas de la Universidad de Harvard; Daniela Maldonado, lideresa comunita- 
ria, activista social y fundadora de la Red Comunitaria Trans, del barrio Santa Fe de Bogotá (Colombia); Ari Vega, mujer trans y directora de Relaciones Institucionales de la Federación Mexicana de Empresarios LGBT; Jacqueline Moraes Teixeira, antropóloga y docente en la Facultad de Educación de la Universidade de São Paulo (Brasil); Dielina Isabel Palomino, investigadora social y activista feminista, coordinadora de la Red de Mujeres Políticas en Expansión, del norte del Cauca (Colombia).

También contamos con la participación de Maribel Nuñez, activista afro, luchadora por el respeto a los derechos humanos, activista de la solidaridad con los pueblos en lucha, periodista y fotógrafa documental de República Dominicana; Eloísa Farrera Hernández, periodista, internacionalista y feminista mexicana; Emilio VillaFuerte, fundador y director ejecutivo de la organización Valientes de Corazón, activista y hombre trans, reconocido por su labor en pro del sector social LGBTIQ en Guayaquil (Ecuador); Las Tesis, un colectivo artístico, interdisciplinario y feminista de Valparaíso (Chile), compuesto por Daffne Valdés Vargas, Paula Cometa Stange, Lea Cáceres Díaz y Sibila Sotomayor van Rysseghem, que se dedica a difundir teoría feminista a partir de performance, específicamente a través de un lenguaje interdisciplinario que combina las artes escénicas, lo sonoro, el diseño gráfico y textil, la historia y las ciencias sociales; Efren Miguel Altamirano, estudiante de periodismo en la Universidad Academia de Humanismo Cristiano de Santiago de Chile y comunicador social de la Universidad Nacional Abierta y a Distancia, de Colombia, que actualmente hace parte de la Colectiva Tan Sólo Tierra, una iniciativa latinoamericana para reflexionar sobre la paz y el territorio; y Adriana Borda "Drixie”, feminista interseccional, antiespecista, bisexual, queer, disidente, activista-artista, pronta titulada de la carrera de Psicología, en La Paz (Bolivia).

Agradecemos de igual manera a cada uno de los y las invitadas a los tres días del ciclo de conferencias por su apoyo, motivación y entusiasmo para configurar este espacio tan importante y enriquecedor. Espe- 
ramos que esta iniciativa de narrar sus valiosas propuestas refleje la dimensión de sus aportes. Adicionalmente, queremos agradecer a las y los compañeros de las maestrías en Estudios Culturales y en Estudios de Género el trabajo colectivo en los diálogos de construcción y configuración de los foros y luego su realización. De igual manera, a las profesoras Martha García y Ochy Curiel, por su apoyo y complicidad en todos los momentos de la organización.

Centrado en la movilización social y los estallidos de protestas a lo largo del continente, el ciclo de conferencias del foro De la Sopa de Wuhan al Sancocho Latinoamericano fue un espacio de articulación de trabajo interdisciplinar y de apuesta política en época de pandemia, creado desde nuestras inquietudes como estudiantes, junto con las compañeras de la Maestría de Estudios de Género y en acompañamiento de Ochy Curiel y Martha C. García, docentes de la Universidad.

El título del foro hace referencia a la compilación de ensayos publicado en marzo del 2020 y que proponen comprender este mundo confinado. El documento fue ampliamente difundido en América Latina y el Caribe

Figuras 1-3. Piezas gráficas con los participantes en los tres días del ciclo de conferencias del foro De la Sopa de Wuhan al Sancocho Latinoamericano (archivo propio).

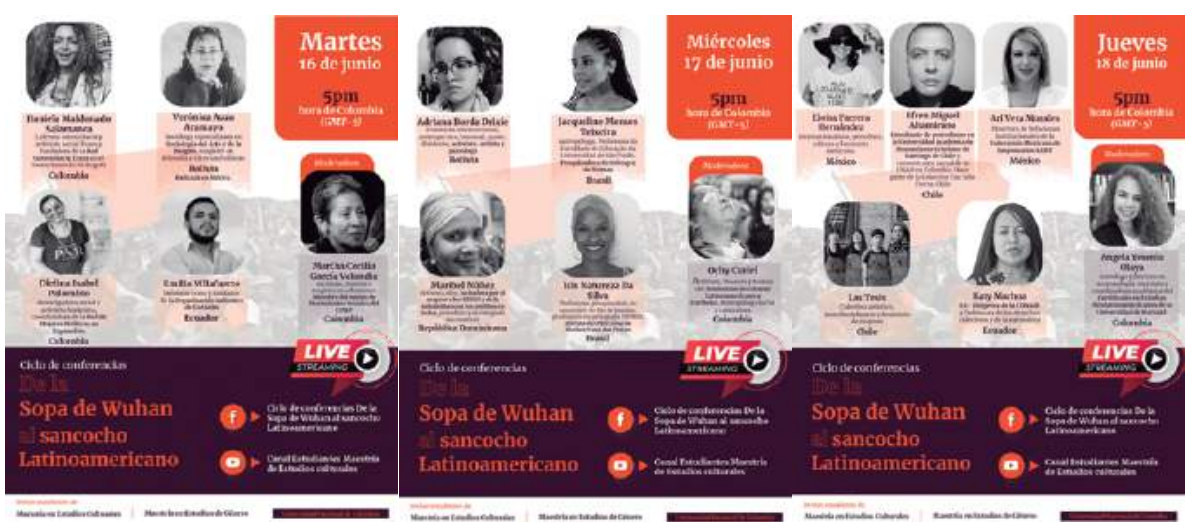


tanto por sus ideas como por una parte de su título: Sopa de Wuhan. ¿Qué nos dice esta expresión que aduce a tan solo dos elementos? Que el hecho de que todas y todos esos intelectuales que se sentaron a pensar sobre el virus tendría que ver necesariamente con un plato - sopa de murciélago- y una localización -China- Así fue como precisamente se desató la polémica alrededor del título. Por una parte, este reproducía el racismo y la exotización de lo no occidental, y sobre todo, infería la culpa de Oriente en la situación. Por otra parte, desde los contenidos mismos, también se identificaba cierto eurocentrismo académico, al ver que la mayoría de las voces hablaban sobre y producían desde Europa, Norteamérica y, en general, el Norte Global, con el que América Latina y el Caribe sostienen una relación colonial.

Ahora, si tomamos la analogía por sí sola, ¿qué pasaría si a la Sopa de Wuhan le adicionáramos gobiernos neoliberales con políticas de exclusión, persecución de sujetos subalternos o la conformación de varios y masivos procesos de movilización social? Allí ya no estaríamos hablando de una sopa, sino de un sancocho, y, propiamente, un sancocho latinoamericano. ${ }^{2}$

Es así como en la propuesta del foro se configuraron nuestras inquietudes por entender, de una parte, en qué circunstancias llegaba el virus a un continente que ya tenía dinámicas conflictivas y de movilización propias, y, de otra, la consideración de que la comprensión del mundo que estaba generando esta pandemia no podía ocurrir sin la integración de América Latina y el Caribe y sus diversas voces: las voces de los protagonistas de movimientos sociales, políticos y culturales que han luchado durante décadas contra lo que este virus está resquebrajando en todas partes.

2 Con sancocho latinoamericano no nos referimos al concepto de Magaly Espinosa ni a la famosa frase de Jaime Bateman, sino al sentido metafórico del nombre del plato de esta región del planeta, que por la variedad de ingredientes que lleva aplicaba muy bien a la mezcolanza de protestas y procesos de movilización con las crisis generadas por la pandemia. 
Nuestras invitadas de Chile, Colombia, México, Ecuador, Bolivia, República Dominicana y Brasil articularon su trabajo personal como activistas en distinto orden, con un análisis de los levantamientos que tuvieron lugar a finales del 2019 y nos permitieron vislumbrar no solo las realidades concretas que se vivían en cada uno de sus países, sino también encontrar puntos en común con los malestares, incertidumbres, propuestas y posibilidades, de cara a un panorama de aislamiento que paralizó las movilizaciones y apropiaciones de las calles, pero no la inconformidad que vivíamos. De esa forma, nos mostraron un horizonte de muchas preguntas que hacía frente a la indefinición y la incertidumbre de la pandemia, a lo incontrolable de una situación de abandono social y de desarticulación, que solo nos dejaba la fuerza para aferrarnos a las redes que se construyeron previamente durante el trabajo colectivo del 2019, y que nos obligaba a volcarnos a aquellas instancias en las que fuera posible construir espacios de lucha, ahora desde la virtualidad. Todo empezó, como dijo Katy Machado, representante de Ecuador, con "un saludo y un abrazo a la distancia”.

Fue así como, enmarcadas en las movilizaciones de 2019, cada participante compartió las motivaciones que la llevaron a organizarse colectivamente, resistiendo y denunciando los impactos de las medidas gubernamentales que con particular fuerza recaen sobre las poblaciones históricamente abandonadas y marginalizadas. Se hicieron evidentes en las intervenciones las demandas sobre las situaciones de opresión, exclusión, violencia y desigualdad social que atraviesan las vidas de mujeres, líderes y lideresas sociales, personas negras y de color, comunidad LGBTIQ + , pueblos indígenas y territorios, a través del continente latinoamericano y caribeño. Opresiones de larga data, que han gestado los Estados nacionales y que han desembocado en un malestar general que, finalmente, dio lugar a la construcción de un movimiento social amplio en la continuidad de la denuncia que conectó a Latinoamérica a través de la movilización social como reivindicación y apropiación del espacio público. Esto, como lo mencionó Ángela Yesenia Olaya, moderadora del tercer día de foro, ha servido para dar lugar a un espacio 
de resistencia que está enviando un mensaje de transformación de las estructuras coloniales que aún están cimentadas en nuestros Estados.

Otros elementos en común en el desarrollo mismo de las manifestaciones han sido la criminalización, desde los medios oficiales, de la protesta social, así como las acciones violentas por parte de la fuerza pública contra los y las manifestantes. El elemento de represión, como señaló Daniela Maldonado, ha sido permanente no solo cobrando la vida de las mujeres trans del barrio, sino como lo mencionó Ari Vega, reafirma esa persecución sistemática por la policía y los organismos estatales a personas "no hegemónicas", desde la lectura de la otra u otro, y particularmente desde la diferencia de género. Daniela nos contó cómo emergió la red comunitaria trans y su motivación para participar de las movilizaciones sociales que tuvieron lugar en Colombia, entre noviembre y diciembre del 2019:

Son esas violencias vividas desde el sistema de salud, los liderazgos acallados, la imposibilidad histórica y la exclusión y estigmatización que se han extendido, incluso a espacios de participación y de organización social, en los cuales las voces de las mujeres trans no han sido tenidas en cuenta, generando muertes que a su vez quedan en la impunidad.

Por su parte, Dielina Isabel Palomino subrayó el aumento y recrudecimiento de las violencias políticas hacia las mujeres que tomaron liderazgos o participación política. Muestra de ello, nos recordó, son los asesinatos de Cristina Bautista, gobernadora indígena, y Karina García, candidata a la Alcaldía de Suárez, Cauca. Enfatizó también en la situación de exterminio sistemático de líderes y lideresas, los efectos de la militarización y la destinación de presupuestos para la guerra, generando taras para los liderazgos y los cambios sociales.

El reforzamiento de gobiernos de extrema derecha que se han radicado en el poder, llenos de discursos misóginos, racistas, homofóbicos, sexistas y clasistas, que en el caso particular de Bolivia, Brasil, Haití 
y República Dominicana han significado la necesidad de disputar la configuración de los derechos desde los marcos de valores fuertemente arraigados en tradiciones religiosas fue el tema de Isis Natureza, profesora y licenciada en pedagogía, quien agregó que los movimientos de izquierda que no se han preocupado por estar con las poblaciones en los territorios de las periferias, no han logrado lo que sí ha hecho la derecha llevando su discurso a través de las iglesias.

Como respuesta, los movimientos sociales crean alternativas para espacializar las resistencias a través de otros medios de comunicación y formas de creación de comunidades mediante el arte y la movilización. Hay entonces una contraproducción y una contranarrativa que está gestando y contribuyendo a fortalecer estos procesos de movilidad social. En Ecuador, la población trans masculina, desde el 2015, ha alzado la voz en el marco de la violación a los derechos en el ámbito de la salud. Ha empezado desde entonces a movilizarse de manera colectiva, utilizando recursos propios, encontrando en los medios de comunicación aliados y detractores de su lucha. Desde el norte del Cauca, los proyectos Irradia y Actoría Social Juvenil ejemplifican cómo las organizaciones sociales de mujeres han logrado pasar del ámbito de la reflexión a la acción, a través de un programa radial, y de acciones colectivas de jóvenes estudiantes de colegio. A través de la radio han dado voz y han empoderado a las mujeres, resignificando sus prácticas cotidianas, concediéndoles un lugar protagónico en la producción radial, un espacio que ha facilitado el diálogo entre jóvenes, impulsando cambios sociales que transforman culturalmente el patriarcado. A su vez, la Actoría Social Juvenil ha posibilitado que jóvenes mujeres estudiantes de colegio hagan una construcción del conocimiento en clave intergeneracional.

En Bogotá, desde la Red Comunitaria Trans, ha sido el arte el espacio de resignificación, la herramienta de incidencia política que ha permitido a las mujeres trans del barrio Santafé visibilizar y denunciar sus problemáticas, ponerlas sobre la mesa y conectarse con la gente desde las prácticas performáticas y artísticas. Emergió como colectivo, alrededor 
de unos encuentros que permitían que se unieran lazos de hermandad entre compañeras. Pasaron así de la exclusión a poder expresarse en espacios institucionales, que les permitieron no solo manifestarse a través del arte, sino fortalecer sus habilidades discursivas para hablar con la gente sin caer en la revictimización. En República Dominicana, movimientos que se convocaron por redes, jóvenes que se visten de negro y exaltan los símbolos patrios. En el caso de Chile, para el colectivo Las Tesis la apuesta ha estado en el trabajo articulado con otras artistas y proyectos que les permiten trabajar desde sus prácticas performativas en la interrupción de la normalidad/cotidianidad y poner el debate sobre otro campo de disputa como lo es el cuerpo, creando una apuesta como el himno "Un violador en tu camino", permeando las manifestaciones feministas y dando la vuelta a todo Abya Yala.

Era importante, y lo señalan con énfasis, también apostarle a la consideración, revisión y apoyo a la constitución de una fuerza social, con el reconocimiento de propuestas de otros lugares de Latinoamérica y el Caribe que permitan la construcción de alternativas y propuestas de respuesta a las dinámicas estatales. Así, afirman, nos vamos inspirando en los trabajos y apuestas de las y los otros que trabajan por esos mundos, otros por los que vale la pena vivir y que son posibles en el reconocimiento de esas iniciativas poderosas que van más allá de nuestras ciudades, que nos implican un trabajo, como dice Katy Machoa, de compromiso y de estar a la altura de los acontecimientos "en el diciendo haciendo (...) hacemos lo que decimos: es la política de los de abajo”.

Fue así como en medio de la pandemia, que puso en pausa las movilizaciones y sobre la mesa un panorama de agudización de las crisis, de preguntas, indefiniciones e incertidumbres, también se gestaron posibilidades de trabajo, de redes interconectadas que fueron más allá de nuestra ubicación geográfica, y que hoy nos sirven como apoyo desde la distancia y nos permiten empezar a trabajar retomando aquello que se aprendió en el curso de las movilizaciones del 2019. El horizonte está en poder tener la utopía, la esperanza, la capacidad emocional, el 
corazón y el pensamiento, para reinventarnos de tal manera que nos permita transformar esta realidad.

Se pone de manifiesto, entonces, la falsa idea de que el virus es democrático porque se han contagiado personas de clases altas que han viajado y regresan infectadas, las cuales son rápidamente tratadas. Lo cierto es que la pandemia ha recrudecido las desigualdades históricas en nuestros países. La pandemia ha sido experimentada de manera diferenciada por mujeres y por hombres, nos recordaba Jacqueline Moraes. Además, se creía entonces que el recrudecimiento de las situaciones de desigualdad y marginación que vivíamos en el aislamiento era el resultado de la pandemia; no obstante, nuestras invitadas hicieron un llamado a entender que estas desigualdades sociales obedecen a procesos históricos de exclusión, segregación y negación de derechos a ciertos grupos sociales, y que están lejos de ser un efecto simplemente de la coyuntura actual.

Cuando las demandas nos mueven durante la contingencia a preguntarnos: ¿Qué es lo prioritario?, Isis Natureza nos recuerda que, como en toda América Latina, en Brasil se han venido organizando desde antes de la pandemia, y con la crisis de la COVID-19 algunas redes de solidaridad se han fortalecido y organizado mejor. Los movimientos negros están cuidando a las personas que no tienen ni siquiera los implementos para procurarse su aseo personal, porque el Estado no está allí sino para aplicar sus políticas genocidas. Estos movimientos han resistido al sabotaje de los gobiernos y su necropolítica. Hay una voluntad y una conciencia colectiva, de un pueblo que tiene dignidad. "Somos un pueblo con dignidad y esa dignidad la vamos a seguir sosteniendo”, agregó Katy Machoa en su intervención.

De la rabia, la indignación, el enojo, emociones que encontraron un lugar y se tejieron en nuestra práctica afectiva con sentimientos como la incertidumbre, pudimos gestionar un espacio de apuesta política como lo fueron los tres días de foro y todo el trabajo detrás que implicó la 
organización en los meses que le precedieron, y que nos permitió reunir invitadas maravillosas en un espacio para dialogar y construir redes desde la experiencia diferenciada en cada caso de movilización en Latinoamérica y el Caribe. En palabras de Daniela Maldonado, "nos hace mover la rabia y el miedo a morir y a quedar en impunidad”. Nuestra motivación, entonces, fue resignificar la rabia y el miedo para movilizar las intencionalidades alrededor de una necesidad de articulación y trabajo comunitario, de complicidades creativas que lograron traducirse en acciones políticas en toda su amplitud. Nuestra apuesta fue clara por una academia crítica, decolonial y siempre dialogante con los movimientos sociales, unida desde la multiplicidad de voces y desde la fuerza de las posibilidades de movilización.

\section{C.) Conclusión: el estado de emergencia no es la excepción, sino la regla}

Mares de tinta han corrido en los que se han citado a Walter Benjamin para explicar los estados de sitio, las dictaduras, el terror, el caos de los Estados nacionales modernos en Occidente bajo la siguiente frase: "La tradición de los oprimidos nos enseña que el 'estado de excepción' en que vivimos es la regla” (Sánchez y Piedras. 2011). Pero momentos coyunturales como la pandemia de la COVID-19 y los aislamientos obligatorios impuestos por los gobiernos nacionales en todo el mundo demuestran que no son frases de cajón destinadas a adornar las citas de académicos y escritores. Situarnos en este momento, bajo el manto del contextualismo radical que hemos defendido en este texto, nos permite ver entre las rendijas de nuestros encierros lo complicado que es vivir en un estado de sitio constante pero fraccionado. Esas fracciones, aunque parezcan desperdigadas en el continente, comparten la angustia de unas opresiones cada vez más afianzadas, unidas con hilos tan finos que se nos hace difícil diferenciar. No todos y todas sufren las opresiones de la misma manera, las violencias que pueblos indígenas, afros, LGBTIQ + , mujeres, niños y niñas, campesinos, obreras, mineros, las y los oprimidos no serán equivalentes a aquellas que con cinismo 
Figure 4. Grupo de trabajo del ciclo de conferencias De la Sopa de Wuhan al Sancocho Latinoamericano (archivo propio).

\section{ID) ]ล \\ Sopa de Wuhan \\ 福 sancocho \\ Latinoamericano}

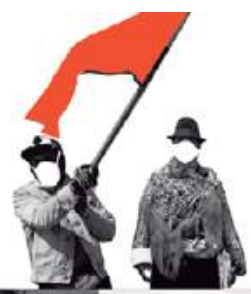

Queremos hacer visibles los rostros de quienes estuvimos detrás de la organización de este evento

Agradecemos a todas y todos lxs que nos apoyaron con esta iniciativa, creyeron y participaron en la posibilidad de un espacio de creación y complicidad colectiva.

Que las reflexiones y discusiones construidas a lo largo de este foro fortalezcan un Abya Yala unida desde la multiplicidad de voces y desde la fuerza de las posibilidades de movilización.

las voces gobernantes vociferan como falsas o contradictorias al curso del desarrollismo. En nombre del progreso Abya Yala ha sido saqueada, ninguneada, relegada al tercer mundo, el patio del primer mundo, una despensa con tiempo de caducidad.

En un ejercicio de volver al pasado y entender este presente que nos arrebata ciertas libertades que creímos ganadas, la movilización social se abre ante nuestros ojos como escenario fértil de prácticas y senti- 
dos que desafían constantemente los preceptos de una normalidad que aceptó el estado de sitio como una política estatal legítima. El enemigo invisible lo han pintado redondo, con puntas que salen de su cuerpo, microscópico, letal, un virus aterrador que mata sin distinción de clase, color de piel, sexo, etnia, edad. ¿Es acaso esto cierto? ¿Quiénes son las personas que más han muerto y padecido el encierro y la precarización de seguridad social en los territorios? Y, ¿a quiénes les importa?, ¿al presidente? ¿a los gobernantes? ¿a las alcaldesas y los alcaldes?

La pandemia nos ha revelado, además de la profunda desigualdad, también las actitudes indiferentes y déspotas de las que no se escapa nadie, ni siquiera quienes escribimos este artículo. La solución ha sido encerrar a todo el mundo para intentar preservar una normalidad que mata más gente que la propia COVID-19. La fragilidad de la vida nos sitúa en un campo de disputas con las normas morales, con el deber ser, con los valores ciudadanos, con eso que ahora llaman 'gente de bien'. La 'gente de bien' acepta y calla que en un país como Colombia sea más fácil morir a manos de "no se sabe quién”, por ser disidentes, por ser el joven que sale a marchar y gritar sus inconformidades, por ser líder o lideresa social, por ser mujer, por ser sujetos racializados, en quienes recaen varias opresiones, convirtiéndose así en el blanco de los mayores impactos de esas violencias sistemáticas que sufren los grupos marginalizados.

Las problemáticas de la educación pueden parecer inconexas antes y durante la COVID-19. Nada más lejano a lo que hemos podido analizar desde nuestra experiencia narrada en la primera parte. Durante el paro nacional de Colombia en el año 2019, las problemáticas que desnudaron desigualdades profundas que hay en las universidades públicas se recrudecieron con las cuarentenas y la emergencia social decretada por el Gobierno nacional del presidente Iván Duque: la privatización de las universidades públicas, la desfinanciación escalonada de presupuestos nacionales para la educación pública, las dificultades de acceso y cobertura, las deplorables condiciones del equipamiento y el mobi- 
liario en los campus, y un largo etc. Además de las tragedias que cada quien vivía y afrontaba con el estado de emergencia: despidos masivos, precarización laboral, sistemas de salud colapsados, pérdida de seres queridos, discriminación y actos de odio hacia extranjeros; crisis emocionales, angustias, dolor y sufrimiento.

¿Cómo afrontar la pandemia? Lo que aprendimos del paro nacional en Colombia y del ya mítico $21 \mathrm{~N}$ es la solidaridad. No es una palabra que deba tomarse con ligereza, es verdad que puede resultar mezquina en escenarios de pugna, claramente vistos con los ataques de odio contra mujeres, contra jóvenes, líderes y lideresas o personas extranjeras a quienes, muy al estilo del chivo expiatorio (Girard, 2005), fácilmente se les acusa de ser los y las culpables de todos los males sociales. La solidaridad no se da por arte de magia, no nace de manera innata, aunque si bien es cierto, debe existir entre las personas un elemento importante para tejerla: la empatía. Sentimientos que empezaron a articularse con sentidos que fuimos creando como grupo, sobre lo que significa el trabajo colectivo, lo que se requiere para elaborarlo, sostenerlo y reflexionar al respecto. Retomando a Margaret Wetherell (2012), hablaríamos de la solidificación de unas prácticas afectivas que nos han permitido coordinarnos, plantearnos preguntas y actuar, en la reflexión conjunta sobre un proceso, sobre una crisis, e incluso en la escritura.

En las plazas, en los salones, en los auditorios, en los coliseos, en estos espacios que pueden carecer de significado para quienes no han estado y vivido en las universidades, particularmente públicas, se consolidó un movimiento que aún teje caminos de solidaridad. Aunque las movilizaciones sociales parezcan oleadas de agua que con fiereza golpean las puertas de los centros de poder de los territorios que habitamos, y que luego se recogen y se desvanecen con el tiempo, sufriendo los típicos ataques de falta de consistencia y constancia de los y las opinadoras, las olas se componen de pequeñas partículas de agua que siguen unidas, que continúan enlazadas; son redes de solidaridad, amistad y trabajo que son difíciles de disolver, y son esas mismas partículas las 
que con fuerza y tenacidad vuelven a unirse a otras para crear olas cada vez más gigantes.

Los foros fueron esos escenarios en los que se unieron múltiples voces privadas de la libertad de marchar en las calles, para reclamar lo que es suyo, nuestro: las ciudades, los campos, las plazas, los centros de estudio, los muros, las avenidas, los puentes, las lomas, las estatuas. En suma, la reivindicación y apropiación del espacio público como un lugar de lucha colectiva. Aunque parezcan tan diferentes, la herencia colonial se siente igual en todos los países del continente americano. Y entre las voces, esta idea recurrente de la aproximación de fuertes tiranías que se abalanzan para reclamar, a costa de la seguridad, esta idea tan frágil que es el progreso, aunque paradójicamente tan fuertemente afianzada en los sentidos de vida de todas y todos en este mundo; es una idea que no debemos descuidar, pues en estos escenarios de convulsión y crisis sabemos lo fácil que es la instauración de autoritarismos.

Lo que pudimos comprender de estos encuentros virtuales es que las problemáticas que se vivieron y que dieron lugar a los estallidos de movilizaciones a finales del 2019, se identifican como procesos más extensos de problemáticas localizadas y comunes que se expresaron desde un malestar general: privatización de espacios públicos, de la educación; la parcialización de los medios de comunicación; las reformas laborales, pensionales y económicas; la explotación de los territorios y la destrucción de los ecosistemas. Todo ello generó una serie de cuestionamientos y demandas al sistema neoliberal, y la continuidad de la denuncia acerca de las relaciones de opresión que han gestado los estados nacionales con los diferentes grupos sociales, así como la criminalización desde los medios de comunicación oficiales de la protesta social.

Ante tales escenarios convulsos, los movimientos sociales se han ingeniado alternativas para espacializar las resistencias a través de medios de comunicación populares y alternativos, performances corporales, 
educación popular, tomas de espacios públicos para resignificar sus sentidos, expresiones artísticas y estéticas en los territorios, y un sin fin de prácticas que luchan por una reivindicación de los pueblos que consolidan una contraproducción y una contranarrativa que se está gestando y está contribuyendo a fortalecer los procesos de movilidad social en Abya Yala.

Ha sido este proceso de consolidación de nuestras prácticas afectivas, de las experiencias y acciones conjuntas de un grupo situado en una institución específica, en el que interactúan personas con diversas historias personales, repertorios de interpretación y demás, un ejercicio de creación y configuración de una formación social. Comenzó con un esfuerzo por conocernos, con las diversiones y complicidades de la amistad, las inquietudes políticas, ese desorden e ímpetu que describimos como el fuego que nos mueve, las farras en La Parva, la cerveza, el ron y el aguardiente; las lecturas de S. Hall, E.P Thompson, A. Davis, Fanon, Trouillot, Ochy Curiel, S. Rivera Cusicanqui, M. Lugones, entre muchas otras autoras. La conspiración, las tusas, el coqueteo, las tareas de grupo, las discusiones, y luego las videollamadas, la creación de un lugar virtual que llamamos con nostalgia "Parva".

A esto le siguió la idea de los foros virtuales, que comenzó como una propuesta de un día, para responder con las responsabilidades académicas de una sola clase; paulatinamente fueron tomando forma, esculpimos una iniciativa hacia una propuesta transdisciplinar que desbordó los estudios culturales, y le coqueteamos a los estudios de género logrando una alianza potente que brindó una mirada holística de los problemas que se intersectan en lo que Collins (2012) llamó una matriz de dominaciones. Comprender que el racismo es un problema y un mecanismo de control estructural, que no solo por ser mujer se sufren violencias sino que la violencia misma es racializada, o pertenecer a una comunidad étnica, o elegir devenir mujer teniendo órganos sexuales de un varón. Develar los manejos corruptos y viciados de los y las gobernantes, quienes se sustentan en lo que Isis Natureza Da Silva, retomando a Achille 
Mbembe, menciona como necropolítica, un modelo que solo trae muerte, violencia y degradación.

Los tres días de foro nos elevaron el estado de ánimo, nos ampliaron los horizontes de sentido y permitieron consolidar una ola con más gotas de agua dispuestas a resistir y transformar sus realidades y su presente. Todo ello, con los recuerdos y los lazos de esta amistad entrañable, nos ha ayudado a resistir el aislamiento social y la pandemia, y al estado de emergencia que es regla en Colombia desde hace más de 70 años.

\section{Referencias}

Aguilar Díaz, Miguel Ángel. (2011). Del espacio al lugar: un análisis de la consolidación urbana local desde la perspectiva narrativa. Alteridades, 21(41), 145-160.

Astarita, Rolando. (2019). Ola de manifestaciones y levantamientos cada vez más globales. Sin Permiso. Recuperado de https://rolandoastarita. blog/2019/12/14/ola-de-manifestaciones-y-levantamientos-cada-vez-masglobales/\#more-9535

Benjamin, Walter. (1999). El Narrador. En Walter Benjamin, Para una crítica de la violencia y otros ensayos. Iluminaciones IV (pp. 111-134). Madrid: Taurus.

Collins, Patricia. (2012). Rasgos distintivos del pensamiento feminista negro. En Sojouner Truth, Ida Wells, Patricia Hill Collins, Angela Davis, Carol Stack, Hazel Carby, Pratibha Parmar, ... Magdalene Ang-Lygate, Feminismo negros. Una antología (pp. 99-134). Traficante de Sueños.

Estudiantes Maestría Estudios Culturales. (16 de junio de 2020a). De la Sopa de Wuhan al Sancocho Latinoamericano [archivo de video]. Recuperado de https://www.youtube.com/watch? $\mathrm{v}=$ Jnuw1CCN3zU\&t $=3 \mathrm{~s}$

Estudiantes Maestría Estudios Culturales. (17 de junio de 2020b). De la Sopa de Wuhan al Sancocho Latinoamericano [archivo de video]. Recuperado de https://www.youtube.com/watch? $\mathrm{v}=$ j12HdsSPOT0\&t $=10 \mathrm{~s}$

Estudiantes Maestría Estudios Culturales. (18 de junio de 2020c). De la Sopa de Wuhan al Sancocho Latinoamericano [archivo de video]. Recuperado de https://www.youtube.com/watch?v = x6MpjcbK-o8 
Girard, René. (2005). La violencia y lo sagrado (Cuarta ed.). Barcelona: Editorial Anagrama.

Grossberg, Lawrence. (2012). El corazón de los estudios culturales. En Gabriela Ubaldini (Trad.), Estudios culturales en tiempo futuro. Cómo es el trabajo intelectual que requiere el mundo de hoy (pp. 21-76). Buenos Aires: Siglo xXI Editores.

Lindón, Alicia; Aguilar, Miguel Ángel y Hiernaux-Nicolas, Daniel. (2006). Lugares e imaginarios en la metrópolis. México D.F.: Universidad Autónoma Metropolitana, Unidad Iztapalapa.

Sánchez Sanz, José y Piedras Monroy, Pedro. (2011). A propósito de Walter Benjamin: nueva traducción y guía de lectura de las "Tesis de filosofía de la historia”. Duererias Analecta philosophiiae, (2), 1-32.

Wetherell, Margaret. (2012). Affect and Emotion. A New Social Science Understanding. Washington: Sage. Publications Ltd. 